\title{
ON THE GENESIS OF THE 2013 BACHAT EARTHQUAKE
}

\author{
G. G. Kocharyan, S. B. Kishkina, A. M. Budkov, G. N. Ivanchenko
}

Institute of Geosphere Dynamics of RAS, Moscow, Russia

\begin{abstract}
The $M_{L} 6.1$ earthquake that occurred on June 18, 2013 in Kuzbass is the strongest seismic event related to mining operations in this region. Opinions about its genesis differ. On the one hand, its hypocenter and most aftershocks occurred directly underneath the Bachat open-pit mine, which suggests that this seismic event was due to anthropogenic impacts. On the other hand, the earthquake focus was located at a depth of several kilometers, which, according to some authors, argues against the anthropogenic factor - the technogenic change in the parameters of the stress field was insignificant against the lithostatic pressure and, especially, the rock strength (e.g. [Lovchikov, 2016]). Our study aims to discover and assess an impact of the mining operations in the near-surface areas of the crust, investigate whether the Bachat earthquake was caused by the mining operations, and clarify which processes in particular were the most probable triggers of dynamic movement in the Bachat earthquake source. The probable geometrical parameters of the fault plane were estimated from the structural and tectonic conditions of the study area and the published locations of the aftershocks [Emanov et al., 2017]. It is established that seimic events of magnitudes similar to that of the Bachat earthquake cannot be caused by the overall anthropogenic load on the area, and it is unlikely that such a strong earthquake may occur due to the direct effects of seismic vibrations resulting from mass explosions during the mining operations. Our analytical models and numerical simulations, as well as the analysis of seismological observation data show that the most probable factor that initiated dynamic movements in the earthquake source was the extraction of the huge rock volume and its transportation from the Bachat open-pit mine. It should be noted that the size of the zone, wherein the geomechanical initiation criteria are met, is considerably larger than the critical size of a nucleation zone for a M 6 earthquake. However, open-pit mining operations can hardly affect the localization of strong earthquake sources. Mining operations can only trigger a seismic event that has been already prepared by the natural evolution of the crust.
\end{abstract}

Key words: technogenic earthquake; induced seismicity; open-pit mining; mass explosions; earthquake nucleation zone; fault zone; Coulomb stress 


\title{
О ГЕНЕЗИСЕ БАЧАТСКОГО ЗЕМЛЕТРЯСЕНИЯ 2013 ГОДА
}

\author{
Г. Г. Кочарян, С. Б. Кишкина, А. М. Будков, Г. Н. Иванченко
}

\author{
Институт динамики геосфер РАН, Москва, Россия
}

\begin{abstract}
Аннотация: Землетрясение с магнитудой $\mathrm{M}_{\mathrm{L}}=6.1$, произошедшее в Кузбассе 18.06.2013 г., - самое крупное сейсмическое событие, связанное с горными работами. Мнения о его генезисе расходятся. С одной стороны, расположение гипоцентра и большинства афтершоков непосредственно под карьером наводит на мысль о техногенной природе события. С другой стороны, очаг располагался на глубине нескольких километров, что, по мнению ряда авторов, свидетельствует против этого предположения из-за незначительной величины техногенного изменения параметров поля напряжений по сравнению с литостатическим давлением и, тем более, с прочностью породы [Lovchikov, 2016; и дp.] В настоящей работе предпринята попытка разобраться, в какой мере горные работы в приповерхностных областях коры способны стать причиной крупного землетрясения и какие именно процессы могут оказаться наиболее вероятным триггером динамической подвижки в очаге Бачатского землетрясения. Вероятные геометрические параметры плоскости разрыва получены в ходе анализа структурно-тектонической обстановки региона и опубликованных сведений о местоположении афтершоков [Emanov et al., 2017]. Показано, что инициирование событий такого размера общим уровнем антропогенной нагрузки на регион или непосредственным воздействием сейсмических колебаний от массовых взрывов маловероятно. В результате использования аналитического и численного моделирования, а также анализа данных сейсмологических наблюдений удалось продемонстрировать, что наиболее вероятным фактором инициирования динамической подвижки в очаге является извлечение и перемещение горной породы из карьера такого масштаба, как Бачатский. Следует отметить, что размер зоны, в которой выполняются геомеханические критерии инициирования, существенно больше критического размера зоны нуклеации для землетрясений с магнитудой М 6. При этом открытые горные работы едва ли влияют на локализацию очагов крупных землетрясений: они способны только приблизить момент события, уже подготовленного естественной эволюцией коры.
\end{abstract}

Ключевые слова: техногенное землетрясение; индуцированная сейсмичность; открытые горные работы; массовые взрывы; зона нуклеации землетрясения; разломная зона; кулоновское напряжение

\section{1. ВВЕДЕНИЕ}

Хорошо известно, что одним из проявлений антропогенного воздействия на земную кору считается наведенная сейсмичность - землетрясения, так или иначе связанные с инженерной деятельностью. Хотя подавляющее большинство из них очень слабые, магнитуда некоторых событий достигает значительных величин. Самое большое землетрясение, инициированное инжекцией флюида, имело магнитуду $\mathrm{M}=5.8$ и произошло в 2016 г. в Оклахоме (США). Крупнейшее землетрясение $\mathrm{M}=7.3$, связанное с добычей газа, случилось в Газли (Узбекистан) в 1976 г. В ряде публикаций утверждается, что и Венчуанское землетрясение в Китае, 2008 г., М 8, и землетрясение Горха в Непале, 2015 г., M=7.8, также инициированы человеческой деятельностью [Foulger et al., 2018, и ссылки в этой работе], хотя обоснованность этих предположений пока оставляет желать лучшего.

Известно, по крайней мере, несколько сотен землетрясений с $\mathrm{M}>2.8$, которые связывают с добычей твердых полезных ископаемых на предпри- ятиях Австралии, Китая, России, Южной Африки и других регионов [Heesakkers et al., 2011; Foulger et al., 2018; $и \partial p$.].

Для обозначения этих явлений в русскоязычной литературе используют различные наименования: горно-тектонический удар, техногенное, техногенно-тектоническое, природно-техногенное землетрясение, подразумевая антропогенную причину их возникновения при естественном источнике энергии деформации [Shemyakin et al., 1986; Lovchikov, 2013; Adushkin, 2016; и дp.]. Очаговые области крупных событий либо связаны с обрушением больших площадей выработок, вследствие разрушения целиков, либо представляют собой подвижки по разломам и тектоническим трещинам [Melnikov, 2002; Kocharyan, 2016; Heesakkers et al., 2011]. В последнем случае источники сильных событий могут располагаться на значительном удалении от шахты или карьера. Гипоцентры природно-техногенных событий порой находятся на значительной глубине (5-10 км) [Adushkin, 2016; и дp.].

В горном деле техногенные землетрясения чаще всего ассоциируются с подземными горными рабо- 
тами, проводящимися на больших глубинах в массивах со значительной тектонической составляющей поля напряжений. Одно из первых документально подтвержденных крупных $\left(\mathrm{M}_{\mathrm{L}}=5.3\right)$ землетрясений такого рода произошло в Австралии 18.12.1925 г. [Foulger et al., 2018]. Землетрясения, ассоциированные с выемкой породы в карьерах, относятся к категории довольно редких проявлений техногенной сейсмичности. Тем не менее самое крупное сейсмическое событие, инициированное горными работами, связано, как это ни странно на первый взгляд, именно с добычей угля открытым способом. Это землетрясение с магнитудой $\mathrm{M}_{\mathrm{L}}=6.1$ произошло 18.06.2013 г. в Кузбассе, в непосредственной окрестности Бачатского угольного разреза. Интенсивность колебаний в эпицентральной зоне землетрясения составила $\mathrm{I}_{0}=7$ баллов. В 5-балльную зону попали города Кузбасса, землетрясение ощущалось и за пределами Кемеровской области [Emanov et al., 2014, 2017].

Мнения о генезисе Бачатского землетрясения, приведенные в литературе, подчас расходятся. С одной стороны, расположение гипоцентра и большинства афтершоков непосредственно под карьером наводит на мысль об индуцированной природе события. Ряд авторов считают несомненным, что землетрясение было инициировано техногенной деятельностью [Emanov et al., 2014, 2017; Batugin, 2015; Adushkin, 2016; и дp.], приводя, впрочем, в качестве аргументов лишь общие соображения о влиянии разрушения, извлечения и перемещения значительных объемов горной породы, об изменении существующих в массиве естественных геодинамических и гидродинамических режимов под воздействием комплекса техногенных нагрузок [Adushkin, 2016] или о снижении нормального сжатия пологонаклонных сместителей взбросов [Batugin, 2015]. Еще одним фактором, с которым связывают инициирование землетрясений, является регулярное воздействие на горный массив промышленных взрывов с суммарным весом заряда в сотни тонн. Здесь тоже дело не идет дальше общих слов о влиянии «...потоков сейсмической (кинетической) энергии, создаваемых массовыми взрывами. Эти динамические воздействия порождают вибрационно-колебательные движения и относительные смещения блоковых структур земной коры, а также необратимые деформации по контактам и зонам разломов, приводя к концентрации на них тектонических напряжений как очагов землетрясений» [Adushkin, 2018].

С другой стороны, авторы ряда работ, проведя численные расчеты, апеллируют к тому обстоятельству, что расположение гипоцентра на глубине нескольких километров свидетельствует о слабом влиянии горных работ [Reshetnyak et al., 2012]. Не вполне, на наш взгляд, корректное сопоставление изменения величины напряжений с литостатическим давлением и, тем более, с прочностью породы приводит к заключению, что «...горные работы по выемке угля из Бачатского карьера не могли быть причиной Бачатского землетрясения 18.06.2013 г. ввиду незначительного изменения напряженнодеформированного состояния вблизи его окрестности, вследствие чего это землетрясение нельзя считать техногенным» [Lovchikov, Savchenko, 2016], или «...выемка угля и породной массы Бачатским карьером ни в коей мере не могла спровоцировать техногенное землетрясение, тем более такой мощности $\left(\mathrm{M}_{\mathrm{L}}=6.1\right) »[$ Lovchikov, 2016].

В настоящей работе сделана попытка разобраться, в какой мере горные работы в приповерхностных областях коры способны стать причиной крупного землетрясения, и какие именно процессы могут оказаться наиболее вероятным триггером динамического выделения части энергии деформации, накопленной в массиве горных пород. При этом будем исходить из того, что излучение сейсмических волн при землетрясении значительной магнитуды происходит в результате динамического перемещения вдоль существующего тектонического разлома.

\section{2. ОЦЕНКА ХАРАКТЕРНОГО РАЗМЕРА ЗАДАЧИ}

При рассмотрении деформационных процессов, происходящих в окрестности горнодобывающего предприятия, в качестве первого характерного геометрического параметра выступают собственно размеры карьера - длина, ширина, глубина. Понятно, что изменения естественного поля напряжений в рамках упругого решения будут определяться именно этими параметрами, а влияние вариаций физико-механических характеристик породы будет сказываться не столь значительно.

Бачатский карьер в 2013 г. имел следующие размеры: длина - 10 км, ширина - 2.2 км, глубина 320 м [Emanov et al., 2014]. Оценка влияния подобной выемки на параметры поля напряжений в массиве будет выполнена ниже.

Вторым важным геометрическим параметром, определяющим размеры области, в которой следует изучить влияние горных работ, является длина разрыва и его положение в пространстве. Хотя известно, что область подготовки землетрясения существенно превышает размеры очага, в контексте процесса инициирования, очевидно, необходимо рассматривать именно область зарождения и распространения процесса скольжения. Вариация в этой области напряженного состояния из-за снижения массы вышележащих пород или изменения 
характеристик материала (например, благодаря проникновению флюида) может инициировать скольжение по разлому.

Сведения о длине разрывов землетрясений разного размера приводятся во многих работах. Обобщение этих данных можно найти в монографии [Kocharyan, 2016], в которой, в отличие от большинства публикаций, собраны сведения о землетрясениях всего инструментального диапазона - от микрособытий с магнитудой $\mathrm{M}<-3$ до крупнейших мегаземлетрясений.

Для крупных землетрясений длина разрыва определялась методом инверсии, по размеру облака афтершоков, из геодезических наблюдений. Для мелких событий - слабых землетрясений, афтершоковых последовательностей, шахтной сейсмичности - радиус источника определялся по угловой частоте спектра излученного сигнала. В качестве характеристики размера события использовалась исключительно величина сейсмического момента. Для крупных событий она определялась по Гарвардскому каталогу (https://www.globalcmt.org). Для слабой сейсмичности использовались лишь те работы, в которых строились спектры зарегистрированных колебаний, а величина $M_{0}$ рассчитывалась по низкочастотной части спектра с учетом станционных поправок. Собранные данные позволили построить ряд регрессионных зависимостей, связывающих величину сейсмического момента и длину очага L.

Для малых событий с моментными магнитудами, лежащими в диапазоне от -4 до +4 , уравнение регрессии соответствует соотношению подобия:

$$
M_{0}=9.2 \cdot 10^{14} \cdot L^{3.0}
$$

с коэффициентом корреляции $R=0.98$.

C увеличением длины очага скорость роста величины $M_{0}$ несколько замедляется. В диапазоне длины разломов 1 км $<L \leq 50$ км

$$
M_{0}=2.90 \cdot 10^{15} \cdot L^{2.39}
$$

с коэффициентом корреляции $R=0.87$.

Заметим, что различия в показателях степени регрессий (1) и (2) соответствуют результатам измерения сдвиговой жесткости разломов и трещин, согласно которым при длине $L \leq 1$ км жесткость обратно пропорциональна длине нарушения, но скорость снижения жесткости сформировавшихся разломов ( $L>1$ км) с масштабом замедляется, по сравнению с несформировавшимися нарушениями (подробнее см. [Kocharyan, 2014, 2016]).

Подчеркнем, что при проведении анализа размеров очага событий $\mathrm{M}<\sim 6.5$ можно пренебречь различиями между землетрясениями с разными механизмами, хотя для более крупных разрывов тектоническая обстановка оказывает существенное влияние на соотношения между параметрами [Wells, Coppersmith, 1994; Kocharyan, 2016]. Таким образом, длину разрыва для землетрясения с магнитудой $\mathrm{M}_{\mathrm{L}}=6.1\left(M_{0} \approx 1.8 \cdot 10^{18} \mathrm{Hм}\right)$ можно приближенно оценить величиной $L \approx 12-15$ км.

Еще одним важнейшим параметром при инициировании динамического процесса является размер зоны зарождения разрыва (зоны нуклеации) участка, на котором скорость разрыва возрастает до динамического значения. В ходе медленного нагружения зона ускоряющегося скольжения прообраз будущего очага - квазистатически увеличивается в размерах. Когда такой участок разлома достигает определенного размера, начинается динамическая стадия. Разрыв выходит за пределы зоны нуклеации и растет с переменной, но сопоставимой со скоростью поперечных волн скоростью до размеров, много больших диаметра первоначального пятна, пока не будет остановлен либо неоднородностью какого-либо вида, либо в силу изменения фрикционных характеристик разлома и/или напряженно-деформированного состояния и упругих свойств вмещающего массива горных пород.

Для того чтобы процесс развивался, необходимо, чтобы размер этой зоны превышал некоторую критическую величину $L_{c}$. Для возникновения фрикционной неустойчивости этот характерный размер определяется выражением:

$$
L_{c} \geq \frac{\eta G D_{c}}{\sigma_{n}(b-a)}
$$

где $G$ - модуль сдвига материала, $\sigma_{n}$ - эффективное напряжение, нормальное к плоскости скольжения, $D_{c}, b, a-$ константы, определяемые фрикционными свойствами контакта, $\eta$ - коэффициент формы величина 1 [Scholz, 1998].

Обсуждение существующих представлений о старте и остановке сейсмогенных разрывов выходит за пределы настоящей статьи. Для нас важно лишь иметь в виду критический размер зоны нуклеации для землетрясений разной магнитуды.

Характерные размеры и времена фаз зарождения сейсмогенного разрыва приближенно оценивают по сейсмологической информации путем детального анализа области первых вступлений сейсмограмм, а также экстраполяцией результатов лабораторных экспериментов и численных расчетов на натурный масштаб. Так, по данным [Papageorgiou, Aki, 1983; Ellsworth, Beroza, 1995; Ide, Takeo, 1997], для приближенных оценок может быть использовано соотношение, связывающее критический размер зоны зарождения разрыва с размером землетрясения: 


$$
M_{0}=8 \cdot 10^{10} L_{c}^{2.39}
$$

В соответствии с (4), характерный размер зоны нуклеации Бачатского землетрясения может составлять $\sim 1000$ м. Заметим, что это значение, скорее всего, является оценкой снизу. Дело в том, что регрессия (4) построена по данным для ряда землетрясений, очаги которых находятся на глубине, типичной для коровых событий, - 10-20 км, тогда как очаг Бачатского события располагался на относительно небольшой глубине в первые километры, а в соответствии с (3), критический размер $L_{c}$ снижается с ростом уровня нормальных напряжений.

\section{3. ГЕОЛОГО-ТЕКТОНИЧЕСКОЕ СТРОЕНИЕ РАЙОНА}

После уточнения характерных размеров очаговой области необходимо рассмотреть тектоническую обстановку региона, с тем чтобы обоснованно предположить, с инициированием каких тектонических нарушений связь Бачатского события наиболее вероятна.

Орографическое положение Кузнецкой впадины определяется ее приуроченностью к западной части Алтае-Саянской области, находящейся между горными массивами Кузнецкого Алатау, Горной Шории и невысоким Салаирским кряжем. Вертикальные смещения по новейшим разломам внутри района минимальны: наиболее активные движения сосредоточены на его границах. Северный и центральный районы Кузнецкого блока образуют современную Кузнецкую межгорную впадину. Центральный район незначительно приподнят относительно северного, высота поверхности выравнивания в его пределах составляет 300-380 м. Максимальной активизации подвергался южный район. Западная окраина Кузнецкого блока в условиях субгоризонтального сжатия интенсивно деформирована в результате надвигания на него Салаирского блока [Avdeyev et al., 2003; Kudinov, 2007]. Coвременное блочное строение района задает серия субпараллельных разломов взбросо-надвигового типа с суммарной амплитудой вертикальных смещений до 2000 м. Крупнейшие взбросы и взбросонадвиги определяют в рельефе три высотные ступени с абсолютными отметками 440-460 м, 380400 м, 320-370 м и ограничивают распространение молодых отложений на северо-востоке и югозападе. В пределах средней высотной ступени выделяются Западная и Центральная тектонические зоны [Kudinov, 2007]. Главными для региона являются высокая степень дислоцированности отложений и линейный характер складчатости. Наиболее интенсивные тектонические процессы (внедрение интрузий и метаморфизм) произошли в этом рай- оне в конце среднего или начале верхнего кембрия (500 млн лет), т.е. в раннекаледонский (салаирский) тектонический этап. К концу каледонского этапа территория района превратилась в складчатую горную страну субплатформенного режима догерцинского этапа тектогенеза. Горизонтальные движения, продолжающиеся до настоящего времени, имеют огромное значение в формировании пликативных структур Присалаирской полосы Кузбасса. Постолигоценовое (неотектоническое) поднятие Салаирского антиклинория повлияло на характер доскладчатых дизъюнктивов, изменив углы их падения с субвертикальных на выполаживающиеся с глубиной, вплоть до субгоризонтальных.

Характер сочленения Кузнецкого блока со смежными геологическими структурами различен (рис. 1,2$)$. Сейсморазведкой установлено, что более древние отложения Салаира по системе шарьяжей надвинуты на молодые отложения Кузнецкой впадины более чем на 20 км. Имеющиеся геофизические данные, в том числе результаты сейсмопрофилирования, позволяют говорить о Салаирском аллохтоне, надвинутом на Кузнецкую впадину по пологим разрывам на глубине 4-5 км, от которых вверх отходят взбросы, образующие серию чешуй, хорошо картируемых на поверхности [Sharov, Chernykh, 2006].

Присалаирская зона надвигов, сформированная движением Салаирского блока на северо-восток в сторону Кузнецкого блока, сохраняет активность на неотектоническом этапе. Здесь на границах разновеликих плит, в том числе Кузнецкого блока и Салаира, имеют место напряжения, вызывающие деформации типа сдвига и торошения горных масс, иногда хорошо выраженные в рельефе [Novikov et $a l ., 2013]$. Активизированные в неоген-четвертичное время разломы формируют блоки с разной интенсивностью и историей неотектонических деформаций. Так, интенсивные тектонические движения отмечаются в среднем неоплейстоцене. Салаир испытал значительное вертикальное поднятие над Кузнецкой котловиной, в зоне сопряжения этих структур образовался уступ высотой до 200 м [State Geological Map, 2007].

Расположение очага Бачатского землетрясения и его афтершоков [Emanov et al., 2014, 2017] показывает, что они приурочены к зоне Кутоновского взбросо-надвига, разделяющего Беловский и Чертинский блоки. Сместитель этого крупноамплитудного разлома, расположенного в окрестности Бачатского угольного разреза, имеет запад-юго-западное падение и северо-запад-юго-восточное простирание. Хотя в приповерхностной части наклон сместителя составляет $30-50^{\circ}$, согласно геофизическим данным [Sharov, Chernykh, 2006], по мере удаления от свободной поверхности разлом быстро 


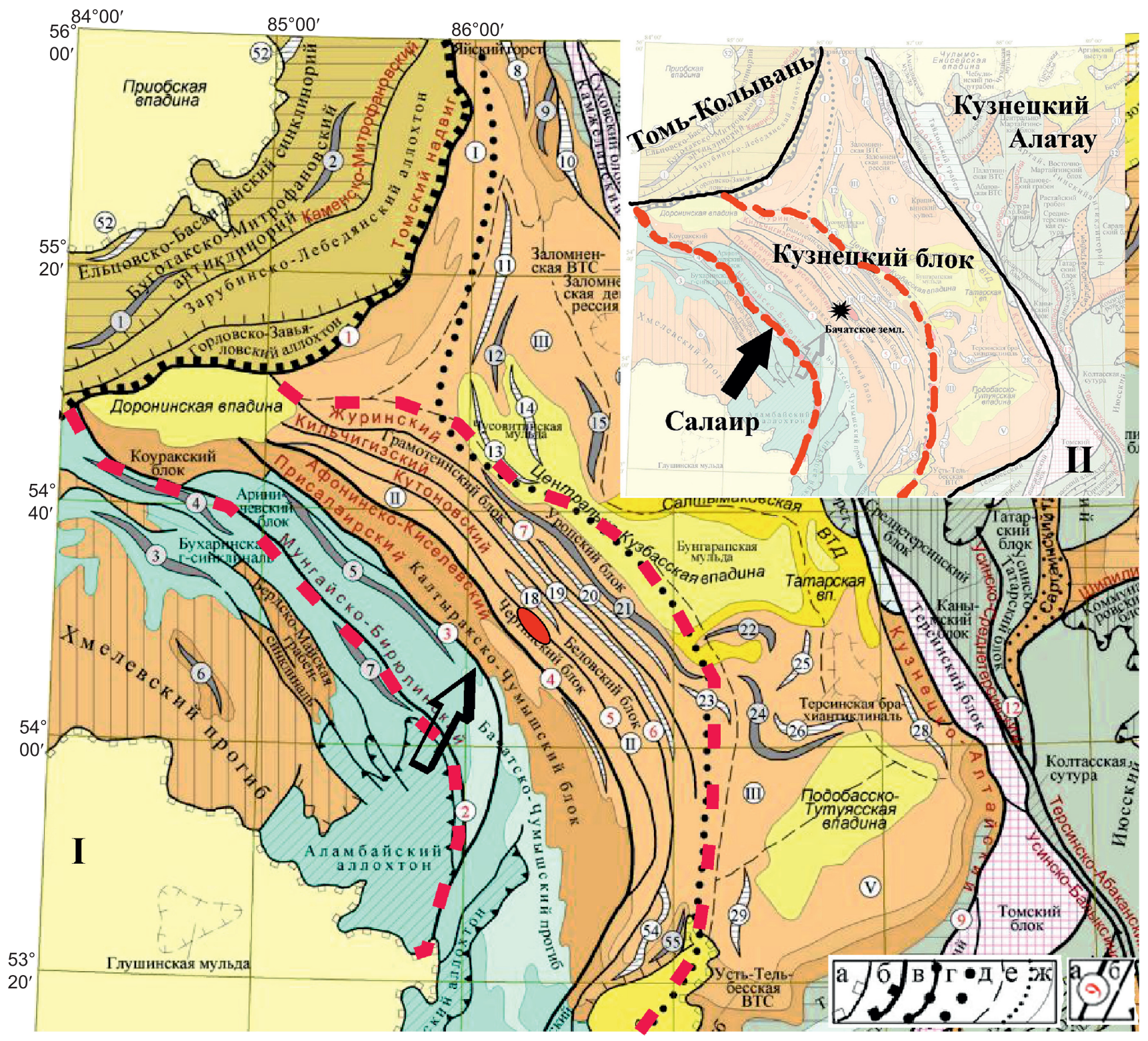

Рис. 1. Геолого-структурная карта (I) и упрощенная структурная схема (II) региона исследований (по [State Geological Map..., 2007]). Красными пунктирами выделена Присалаирская зона надвигов; стрелкой отмечено направление движения Салаирского блока.

Границы: а - Западно-Сибирской плиты, б - складчатых областей (по главному надвигу), в-г - складчатых систем (в - установленные, г - скрытые под более молодыми образованиями), д-е - складчатых подзон (д - установленные, е - скрытые под более молодыми образованиями), ж - стратиграфические.

Разломы, главные (толстые линии), прочие (тонкие линии): 1 - Томский, 2 - Мунгайско-Бирюлинский, 3 - Присалаирский, 4 Афонино-Киселевский (Салаирский), 5 - Кутоновский, 6 - Кильчигизский, 7 - Журинский, 8 - Тайдонский, 9 - Кузнецко-Алтайский, 10 - Кожуховский, 11 - Терсинско-Талановский, 12 - Усинско-Среднетерсинский, 13 - Шипилинско-Сисимский, 14 - Теренсинский, 15 - Бийско-Большереченский, 16 - Сийский, 17 - Аталыкско-Таензинский, 18 - Ташелгинско-Лебедской, 19 - УсинскоБалыксинский, 20 - Терсинско-Абаканский, 21 - Саяно-Минусинский, 22 - Кандатский, 23 - Кабансугско-Амыльский.

Fig. 1. Geological-structural map (I) and simplified structural scheme (II) of the study area (after [State Geological Map..., 2007]). Red dashed lines contour the Prisalair thrust zone; the arrow indicates the displacement direction of the Salair block.

Boundaries: a - West Siberian plate, $\sigma$ - folded zones (along the main thrust fault), В- $\Gamma$ - fold systems (в - confirmed, $\Gamma-$ overlaid by young formations), д-е - folded subzones (д - confirmed, e - overlaid by young formations), ж - stratigraphic boundaries.

Main (thick lines) and secondary (thin lines) faults: 1 - Tomsk , 2 - Mungai-Biryulinsk, 3 - Prisalair, 4 - Afonino-Kiselev (Salair), 5 Kutonov, 6 - Kilchigiz, 7 - Zhurin, 8 - Taidon, 9 - Kuznetsk-Altai, 10 - Kozhukhov, 11 - Tersin-Talanov, 12 - Usinsko-Srednetersin, 13 Shipilino-Sisim, 14 - Terensin, 15 - Biya-Bolsherechensk, 16 - Siya, 17 - Atalyk-Taenzin, 18 - Tashelga-Lebedskoy, 19 - Usinsko-Balyksin, 20 - Tersinsko-Abakan, 21 - Sayano-Minusinsk, 22 - Kandat, 23 - Kabansugsko-Amylsky. 


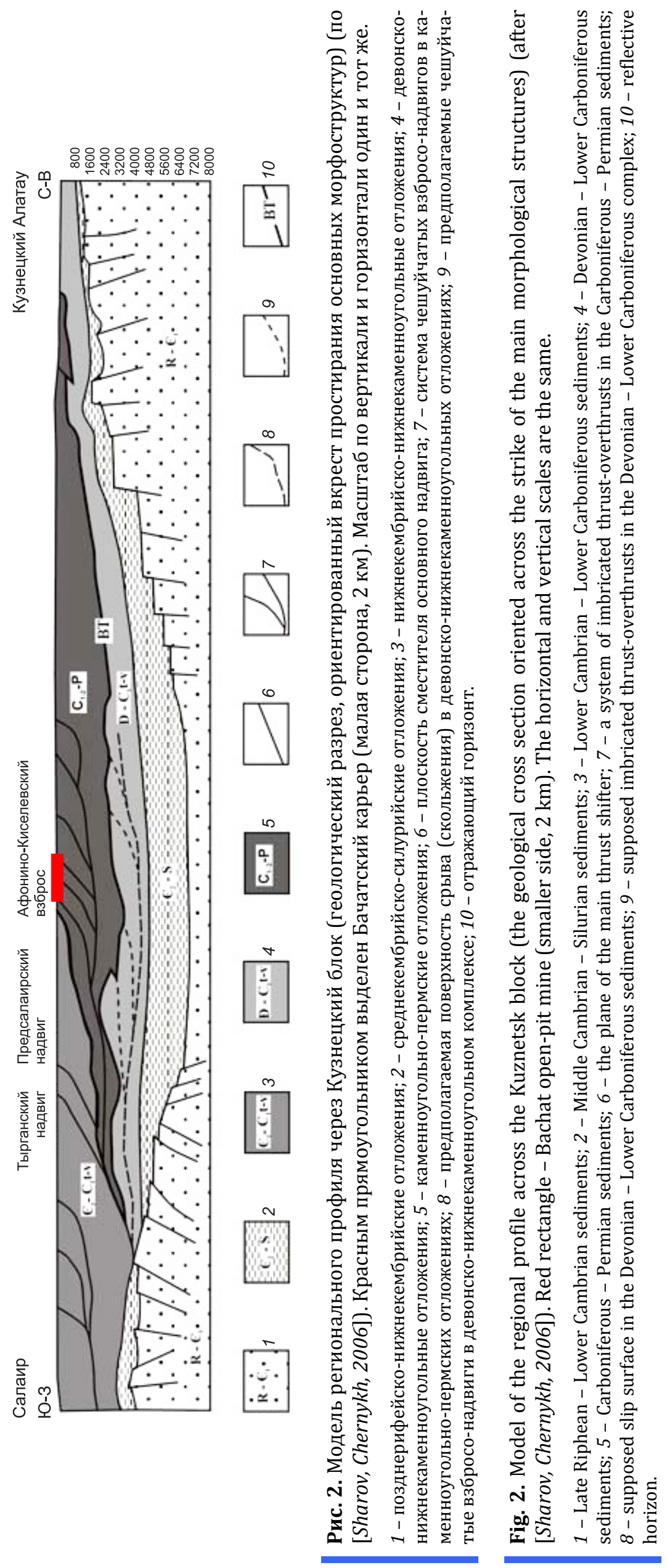


выполаживается и на глубине около 4 км становится почти субгоризонтальным с углом падения около $10^{\circ}$ и менее. Это нарушение является основанием Салаирского шарьяжа, надвинутого на угленосные породы Кузнецкого блока. Угленосные отложения непосредственно в зоне Бачатского разреза собраны в многочисленные складки, различные по форме, величине и площади распространения. Отложения разорваны большим количеством согласных взбросов с амплитудами смещения от 10 до 270 м и более. За счет этого пласты угля в некоторых разрезах многократно повторяются [Lavrenov et al., 2018; Sysoev, Strelyaev, 2007], что позволяет оценивать геометрию взбросов.

Можно полагать, что суммарный эффект сейсмической активизации привел к образованию сейсмотектонических деформаций в зоне уже имеющегося геологического разлома на глубине 4-6 км. Таким образом, при проведении расчетов в качестве сейсмического источника Бачатского события 18.06.2013 г. следует рассматривать подвижку по одному из разломов с параметрами залегания, близкими к Кутоновскому, т.е. с углом падения порядка $10^{\circ}$ на глубине 4-6 км и простиранием СЗ-ЮВ.

\section{4. ВОЗМОЖНЫЕ ПРИЧИНЫ ИНИЦИИРОВАНИЯ ДИНАМИЧЕСКОЙ ПОДВИЖКИ В ОЧАГЕ БАЧАТСКОГО ЗЕМЛЕТРЯСЕНИЯ}

\section{1. ОБЩИЙ УРОВЕНЬ ТЕХНОГЕННОГО ВОЗДЕЙСТВИЯ}

Колоссальный уровень антропогенного воздействия на верхние слои земной коры в Кузбассе заставляет учитывать этот фактор при исследовании региональной сейсмичности. При этом эффективность различных процессов как инициирующих агентов должна быть рассмотрена как с точки зрения общего воздействия на массив, так и с позиций изменения характеристик контактной зоны и вариаций напряженного состояния на вероятной плоскости разрыва.

Как отмечалось выше, в качестве основных причин инициирования достаточно крупных землетрясений при ведении горных работ обычно выделяют изменение параметров поля напряжений вследствие выемки и перемещения больших объемов горной породы, регулярное воздействие на горный массив массовых взрывов, изменение гидрогеологического режима региона из-за откачки воды и/или затопления выработанных объемов.

Хотя горные работы в Кузбассе проводились еще в XIX в., радикальный рост объемов добычи угля начался в ходе индустриализации СССР в 1930-1940-е годы. В 1960-х годах в Кузбассе добывали около 100 млн т угля в год, а к 2018 г. эта

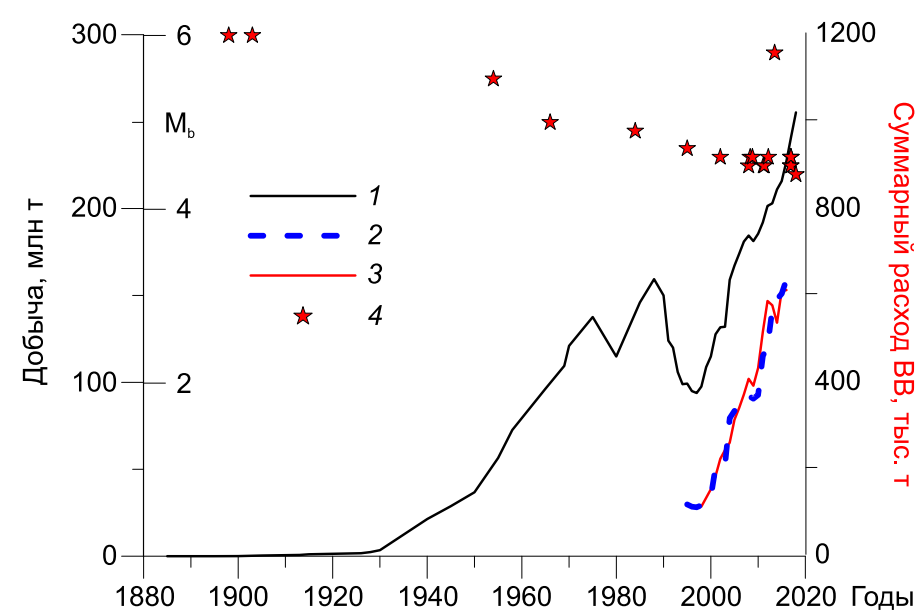

Рис. 3. Данные об объеме добычи и расходе ВВ в районе Кузбасса.

1 - общий объем добычи; 2 - объем добычи открытым способом; 3 - годовой расход ВВ (правая ось ординат); 4 - магнитуда Мb крупнейших землетрясений.

Fig. 3. Mininig volumes and explosive consumption in the Kuzbass region.

1 - total mined volume; 2 - open-pit mined volume; 3 - annual consumption of explosives (right axis of ordinates); 4 - magnitudes $(\mathrm{Mb})$ of the strongest earthquakes.

цифра увеличилась в два с половиной раза 258.3 млн т. Относительно уровня XIX в. добыча увеличилась на пять (!) порядков. Всего извлечено свыше 10 млрд т угля, и перемещена, по крайней мере, не меньшая, а по некоторым сведениям в разы большая масса вскрышной породы. Интенсивно проводятся взрывные работы, масса ВВ при одном взрыве достигает сотен, а иногда превышает и тысячу тонн. Суммарное потребление взрывчатки превысило величину 600 тыс. т в год.

Изменение во времени объема добычи и суммарного расхода ВВ приведено на рис. 3. Здесь же значками показана магнитуда крупнейших землетрясений, произошедших за это время в регионе. Как и следовало ожидать, наблюдается очевидная пропорциональность объема добычи суммарному расходу ВВ (энергии взрывов). Это означает, что разделить действие квазистатических (разрушение массива и выемка породы) и динамических (сейсмические колебания от массовых взрывов, вибрации от работы машин и механизмов) инициирующих факторов путем анализа статистических сведений о сейсмических событиях не представляется возможным.

Крупнейшие сейсмические события происходили и происходят при разном уровне техногенного воздействия. Достоверно известно как минимум о двух сильных землетрясениях с M 6, произошедших задолго до начала интенсивной добычи на 
рубеже XX в. [Ashurkov, 2006]. Это Кузнецкое землетрясение 7(19) июня 1898 г., описанное И.П. Толмачевым в «Известиях сейсмической комиссии», и землетрясение 12.03.1903 г., колебания от которо-

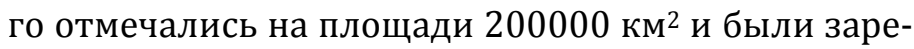
гистрированы сейсмографами.

Основная часть мелких сейсмических событий приурочена непосредственно к месту ведения горных работ и приходится на то время, когда производятся массовые взрывы на угольных разрезах, или через 1-3 ч после них [Yakovlev et al., 2013]. В контексте данной работы наибольший интерес представляют сильные землетрясения, связанные с подвижками по разломам. Чтобы при анализе исключить возможные записи взрывов, были выбраны сейсмические события с $M \geq 4.0$. Обычно магнитуда массового взрыва на крупном карьере составляет величину 2.8-3.2 и слабо зависит от суммарного заряда, поскольку согласно используемым методикам рассчитывается по результатам измерений амплитуды колебаний, которая определяется массой одновременно подрываемого ВВ в группе [Goncharov et al., 2002]. Для Кузбасса магнитуда взрывов по данным [Emanov et al., 2014] не превышает значения $\mathrm{M}=4$.

В работе использовались все доступные данные. Хотя значения магнитуд конкретных событий по разным каталогам заметно отличаются, сопоставление рядов данных для диапазона магнитуд $\mathrm{M}>4$ принципиальной разницы между разными каталогами не выявило. Ниже использованы главным образом данные каталогов ISC (http://www.isc.ac.uk) и Алтае-Саянского филиала ГС РАН (https://www. asgsr.ru). При анализе пространственно-временного распределения землетрясений в районе ведения горных работ многие исследователи отбирают события, произошедшие не в дневное время, что гарантированно исключает из рассмотрения сами взрывы как сейсмические события [Adushkin, 2018]. Еще одно используемое ограничение - выбор сейсмических событий, источник которых определен на глубине, по крайней мере, больше 0.5 км.

Понятно, что ни один из перечисленных способов не идеален. Так, целесообразность исключения «дневных» событий с большими магнитудами вызывает сомнения, поскольку, как отмечалось выше, величина массовых взрывов, проводимых в Кузбассе, заведомо меньше: при выборе только «дневных» событий мы исключаем из анализа целый ряд землетрясений. Например, землетрясение 21.05.1954 г. с M=5.5 г. произошло в 12:12 по местному времени; событие 14.09.1995 г. с М=4.9 в 11:23 [Ovsyuchenko et al., 2011]. При этом следует признать, что неточность в определении магнитуды может привести к завышению количества землетрясений с $\mathrm{M} \sim 3.5-4.0$.

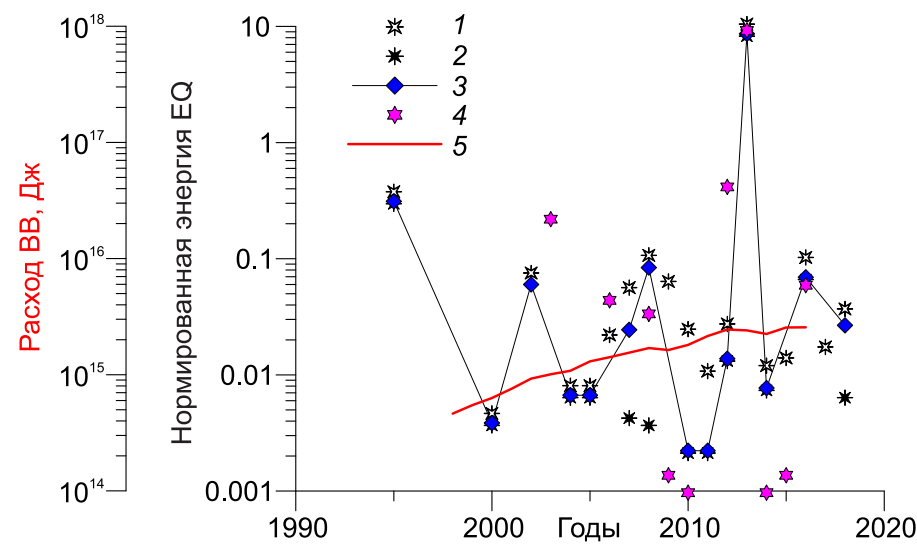

Рис. 4. Изменение со временем энергии, излученной землетрясениями региона, в сопоставлении с ростом суммарного расхода ВВ предприятиями Кузбасса.

1 - все события с М>4; 2 - «ночные» события; 3 - суммарное значение «ночных» событий и событий с М>4.4; 4 - события по данным каталога Алтае-Саянского филиала ГС РАН; 5 энергия ВВ.

Fig. 4. The change over time of the energy released by the earthquakes in the region versus the increase in the total consumption of explosives by the Kuzbass enterprises.

1 - all M>4 events; 2 - 'night' events; 3 - total value of the 'night' events and M>4.4 events; 4 - events in the catalog of the AltaiSayan Branch of GS RAS; 5 - explosive energy.

Выбор событий по глубине также не приводит к успеху: оценка глубины часто не достоверна в условиях недостаточно плотных сейсмических измерений. Например, событие 15.02.1998 г., имевшее, согласно каталогу ISC, глубину 0 км, по данным местных наблюдений являлось землетрясением с глубиной очага 0.8-1.5 км [Yakovlev et al., 2013].

В силу вышеизложенного, для исследования временной связи взрывных работ и крупных землетрясений в Кузбассе мы использовали различные выборки из каталогов: (i) все сейсмические события с магнитудой M $>4$; (ii) «ночные» сейсмические события с $M>4$, зарегистрированные с 18 до 09 часов по местному времени; (iii) совокупность «ночных» событий и событий заведомо большой (M>4.4) магнитуды, произошедших в дневное время, (iv) события с ненулевой глубиной источника $(\mathrm{h}>0.5$ км). Для удобства значения излученной энергии нормированы на среднее годовое значение $\mathrm{E}_{\mathrm{s}}$ для рассматриваемой выборки.

Эти ряды данных приведены на рис. 4. Можно видеть, что ни одна из выборок не демонстрирует четкой временной связи с расходом ВВ. Более того, с учетом того, что ошибка в определении магнитуды $\Delta m= \pm 0.3$ дает разброс в энергии примерно на порядок, вариации годового значения излученной землетрясениями энергии в 1998-2018 гг. (исклю- 
чая 2013 г.) укладываются в пределы погрешности определения магнитуды.

Таким образом, общая техногенная нагрузка на верхнюю часть коры не оказывает очевидного влияния на процесс инициирования крупных землетрясений. Это означает, что необходимо рассматривать непосредственное влияние горных работ на очаговую область каждого события.

\section{2. НЕПОСРЕДСТВЕННОЕ ВЛИЯНИЕ СЕЙСМИЧЕСКИХ КОЛЕБАНИЙ ОТ ВЗРЫВОВ}

Рассмотрим подробнее вопрос о физических предпосылках непосредственного инициирования землетрясения взрывным воздействием. Для начала следует оценить амплитуду сейсмических колебаний в окрестности будущего очага. Обратимся к результатам инструментальных наблюдений за параметрами массовых взрывов. Понятно, что поскольку измерения на глубине нескольких километров никогда не проводились, приходится довольствоваться данными, полученными на свободной поверхности и в шахтах, на глубине в несколько сотен метров.

Результаты многочисленных наблюдений (например [Goncharov et al., 2002, 2006; Kishkina, 2004]) позволяют оценить максимальную скорость смещения грунта в волне на разных расстояниях. Так, типичная зависимость для карьеров КМА, например, имеет вид [Goncharov et al., 2006]:

$$
V_{m}=2050\left(q^{1 / 3} / R\right)^{1.5} \mathrm{MM} / \mathrm{c},
$$

где $q$ - вес заряда в одной ступени замедления, кг, а $R$ - расстояние, м.

При среднем для взрывов на Бачатском карьере значении $q=2.5$ т имеем на расстоянии $R \sim 3-5$ км на поверхности массива значения $V_{m} \sim 0.3-0.6 \mathrm{Mm} / \mathrm{c}$. При этом характерная частота колебаний составляет величину $f \sim 0.1-0.5$ Гц, а длительность цуга может достигать 100 с.

Подчеркнем, что увеличение суммарной массы заряда приводит на таких расстояниях лишь к росту длительности сигнала, но практически не сказывается на значениях максимальной массовой скорости. В глубине массива под центром взрыва частота колебаний будет выше, а амплитуда несколько ниже, чем на свободной поверхности. Соответственно, динамические напряжения в сейсмической волне на глубине 3-5 км могут достигать величин всего в несколько кПа, а деформации $\sim 10^{-7}$ отн. ед.

Обращаясь к опыту исследований триггерного эффекта удаленных землетрясений, отметим, что в большинстве случаев в качестве минимально необходимого для инициирования приводится уровень деформаций 5×10-7-10-6, хотя некоторые авторы указывают и более низкие значения. Подробный обзор этих сведений приведен в монографии [Кocharyan, 2016].

Еще одним обстоятельством, свидетельствующим не в пользу гипотезы непосредственного инициирования землетрясений колебаниями от взрывов, является довольно высокая частота колебаний, тогда как в большинстве случаев возникновение динамически инициированной сейсмичности связывается с воздействием низкочастотных поверхностных волн от удаленных землетрясений. При этом отмечается, что инициирование относительно высокочастотными объемными волнами менее эффективно на больших расстояниях.

Феноменология инициирования землетрясений сейсмическими волнами до конца не ясна. В зависимости от ряда условий, вибрации способны как инициировать крупные события, так и, наоборот, создавать условия для перераспределения накопленной энергии деформации в пользу относительно мелких событий. Судя по данным лабораторных экспериментов, определяющую роль в этом выборе играет фоновый тип режима скольжения, реализованный на разломе [Kocharyan et al., 2013].

Одна из наиболее проработанных механических моделей процесса инициирования динамических событий сейсмическими колебаниями основана на эффекте накопления малых деформаций на напряженном разломе [Kocharyan et al., 2004; Kocharyan, 2012; Bobryakov et al., 2015]. Согласно этой модели, динамическое воздействие приводит к возникновению остаточных перемещений берегов при условии, что трещина или разлом нагружены полем квазистатических напряжений. Величина остаточного перемещения при динамическом воздействии пропорциональна амплитуде инициирующего импульса, длительности волнового пакета и обратно пропорциональна жесткости нарушения.

Знак остаточных деформаций, связанных с динамическим воздействием, соответствует знаку квазистатических перемещений бортов нарушения сплошности. Для приближенной оценки кумулятивной величины перемещения $\Delta$ можно использовать соотношение [Kocharyan, 2012]:

$$
\Delta \approx \alpha \cdot n \cdot \frac{\rho \cdot\left(C_{s} \cdot V_{m}\right)}{k_{s 0}}
$$

где $V_{m}$ - максимальная скорость смещения в волне, $n$ - количество основных циклов в волновом пакете, $C_{S}$ - скорость распространения поперечных волн, $k_{s 0}$ - значение жесткости трещины при малых деформациях, коэффициент $\alpha<1$, зависит от напряженного состояния контакта. В модельных экспериментах параметр $\alpha$ изменялся от 0.04 при $\tau_{s} / \tau_{p} \sim 0.50$ до 0.80 при $\tau_{s} / \tau_{p} \sim 0.99$, где $\tau_{s}$ - напряже- 
ния, касательные к плоскости контакта прочностью $\tau_{p}$. По некоторым оценкам, для природных объектов этот множитель может быть на один два порядка меньше $\alpha \sim 10^{-3}-10^{-2}$.

По мере приближения разлома к пределу прочности величина остаточного перемещения, инициируемого одним и тем же импульсом, увеличивается. Величина «критического смещения» - межблокового перемещения, при котором наблюдается динамический срыв, - не зависит от амплитуды воздействия, а определяется лишь свойствами контакта и его напряженно-деформированным состоянием.

Используя для оценки «сверху» значения $\alpha=0.01$; $k_{s 0} \sim 10^{7-10^{8}}$ Па/м [Kocharyan, 2016], $V_{\mathrm{m}}=0.5 \mathrm{Mм} / \mathrm{c}$, $n=500$, получаем: $\Delta \sim 0.2-2.0$ мм. Эта величина, вероятно, сильно «переоценена». Некоторые результаты прецизионных измерений остаточных перемещений при воздействии сейсмических колебаний от взрывов на разломные зоны приведены на рис. 5. Линией на рисунке показана регрессионная зависимость:

$$
\Delta W=3.2 \cdot V_{m}^{1.06}
$$

построенная методом наименьших квадратов. Можно видеть, что сейсмические колебания с амплитудой, различающейся на 1-2 порядка, инициируют близкие остаточные эффекты, что объясняется различным напряженным состоянием нарушений сплошности. В то же время тренд функции $\Delta W\left(V_{m}\right)$, как и зависимость (6), демонстрирует пропорциональность амплитуде колебаний. То, что остаточные перемещения формируются в результате воздействия колебаний, отчетливо видно на сейсмограмме, показанной на рис. 6.

Таким образом, ожидаемая величина остаточного перемещения при величине максимальной массовой скорости $V_{m} \sim 0.3-0.6$ мм/с составляет порядка десяти микрон, а при самом благоприятном случае не превышает первых миллиметров. При таких величинах перемещений трудно ожидать прямого инициирования землетрясения значительной магнитуды сейсмическими волнами взрыва, поскольку по сейсмологическим данным критическое перемещение для землетрясения с магнитудой $\mathrm{M=6}$ составляет величину порядка $10 \mathrm{~cm}$ [Ellsworth, Beroza, 1995; и др.].

Еще один аргумент, часто используемый при обосновании инициирования землетрясений, - увеличение «энергонасыщенности» массива при воздействии взрыва. Соглашаясь с позицией Ш.А. Мухамедиева [Mukhamediev, 2016] о том, что «...этот термин плохо определен и поэтому потенциально вредоносен..», отметим, тем не менее, что нет основания полагать, что «энергонасыщенность» (плотность энергии, потенциальная энергия системы и

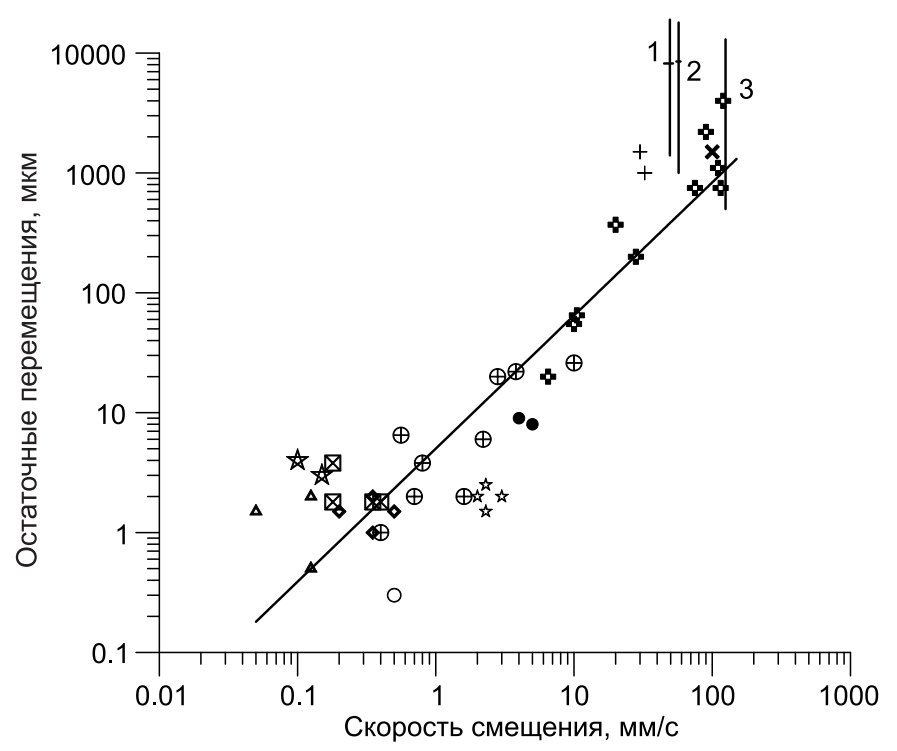

Рис. 5. Зависимость остаточных перемещений, зарегистрированных на нарушениях сплошности, от величины максимальной скорости смещения в сейсмической волне. Значки - результаты измерений на различных природных и инженерных объектах. Линия - регрессионная зависимость (7). Крестики, обозначенные цифрами 1 , 2, 3, - результаты измерения крипа, инициированного землетрясением Hector Mine 1999 г., $\mathrm{M}=7.1$, на разломах Южной Калифорнии по данным [Rymer et al., 2002]: 1 - разлом Imperial Valley, 2 - Superstition Hills, 3 - San Andreas. Размер крестика показывает разброс данных.

Fig. 5. Dependence of residual displacements recorded at the faults on the magnitude of the maximum displacement velocity in the seismic wave. Signs - measurements at natural and engineering facilities. Line - regression curve (7). Crosses with numbers 1,2 , and 3 - measurements of creep initiated by the M 7.1 1999 Hector Mine earthquake on the faults in South California (after [Rymer et al., 2002]): 1 Imperial Valley Fault, 2 - Superstition Hills Fault, 3 - San Andreas Fault. The data scatter is shown by the sizes of the crosses.

т.п.) увеличивается в результате действия массового взрыва. Это легко пояснить при помощи элементарной оценки.

Расход ВВ в Кузбассе составляет около 600 тыс. т/год. Полная энергия, выделившаяся при этих взрывах, составляет величину 2.5·1015 Дж. Большая ее часть переходит в тепло и идет на дробление породы в ближней зоне взрыва, а величина излученной этими взрывами энергии составляет примерно 5·1013 Дж. Масса поднятого на поверхность и вывезенного угля при этом составляет величину $\mathrm{M}=250 \cdot 10^{9}$ кг. Т.е. потенциальная энергия системы уменьшилась за счет потери массы на величину $d E \approx M g H$. Принимая для оценки Н 20 м, получаем $d E \sim 5 \cdot 10^{13}$ Дж. Стала ли среда при этом более «энер- 


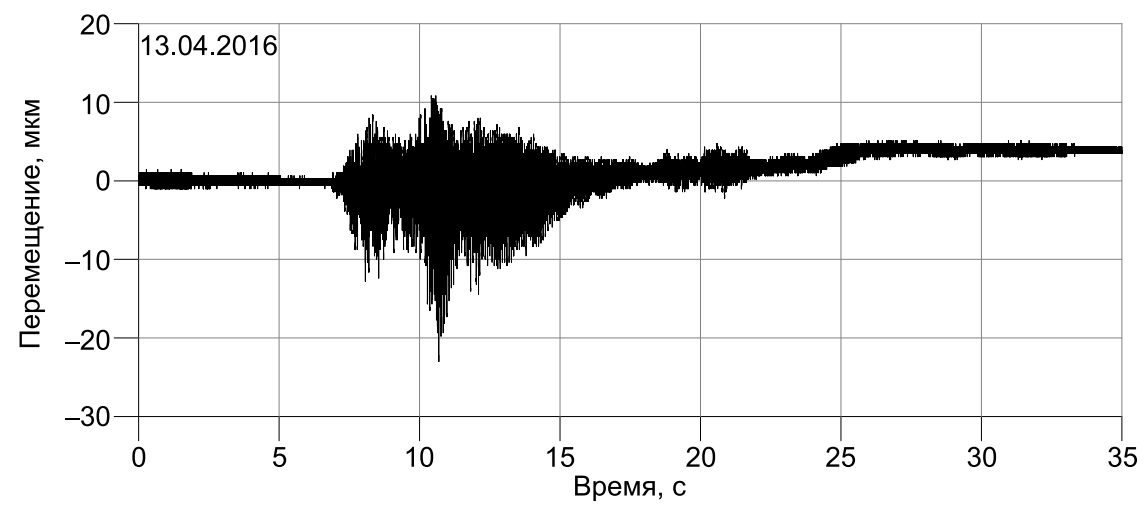

Рис. 6. Запись перемещения берегов разлома под действием сейсмовзрывной волны от массового взрыва на Лебединском ГОКе. Размах амплитуды перемещения $\mathrm{W}_{\mathrm{m}}$ 30 мкм. Хорошо видна остаточная деформация $\mathrm{W}_{\mathrm{r}} \sim 4$ мкм, сформировавшаяся примерно к 23-й секунде записи.

Fig. 6. Recorded displacement of the fault sides due to a seismic blast wave from the mass explosion at the Lebedinsky GOK. Displacement amplitude: $\mathrm{W}_{\mathrm{m}} \sim 30 \mu \mathrm{m}$. Residual deformation: $\mathrm{W}_{\mathrm{r}} \sim 4 \mu \mathrm{m}$ (about the 23rd second of recording).

гонасыщенной», или, наоборот, ее «энергонасыщенность» уменьшится?

Таким образом, оценки эффективности воздействия на массив таких факторов, как объемы добычи и сейсмическое действие массовых взрывов, не дают оснований обоснованно считать их факторами, провоцирующими крупные сейсмические события.

\section{3. ИЗМЕНЕНИЕ НАПРЯЖЕННОГО СОСТОЯНИЯ НА ПЛОСКОСТИ РАЗЛОМА}

Как отмечалось выше, наиболее вероятно, что очаг крупного землетрясения, связанного с инженерной деятельностью, представляет собой подвижку по существующему в массиве активному разлому. Под активным разломом здесь следует понимать тектоническое нарушение с признаками постоянных или периодических перемещений бортов разлома в течение первых десятков тысяч лет, считая от современности. Известные случаи, в которых очаговая область землетрясения пересекала горные выработки и была достаточно подробно обследована (землетрясение 16.04.1989 г. М=4.34.8 в Хибинах, 12.12.2004 г., M=2.2 Южная Африка и др.), подтверждают это положение [Kremenetskaya, Trjapitsin, 1995; Heesakkers et al., 2011].

Ясно, что горные работы, проводимые в карьере, неспособны значимо повлиять ни на упругие характеристики массива на глубине нескольких километров, ни на фрикционные свойства поверхности скольжения внутри разломной зоны. Как было показано выше, непосредственное влияние сейсмических колебаний от взрывов также не обладает значительным инициирующим потенциалом. В этой связи вероятным инициирующим фактором оказывается изменение напряженного состояния на плоскости разлома в результате выемки и перемещения горной породы.

Для приближенных оценок изменения напряженно-деформированного состояния массива в результате выемки породы используем решение задачи Лява [Love, 1927], в которой рассматривается поле напряжений при приложении нагрузки к участку прямоугольной формы на поверхности упругого полупространства. При этом [Florin, 1959] при малой, по сравнению с длиной и шириной, глубине участка приложения нагрузки (в нашем случае это 300 м по сравнению с протяженностью 10 км и шириной 2 км) выемку горной породы глубиной $h$ можно заменить равномерным снятием нагрузки $\zeta_{\mathrm{z}}=\rho g h$. Поскольку нас интересуют порядки величины, возможными искажениями из-за несовпадения геометрии модели с параметрами реального объекта можно пренебречь.

Аналитическое решение задачи Лява, описывающее изменения величин напряжений и перемещений в зависимости от координат в виде соотношений, приведенных в работе [Korotkin, 1938], было использовано нами для расчета параметров поля напряжений в окрестности Бачатского карьера.

Результаты расчета демонстрируют, что на глубине 4-10 км изменения главных напряжений, вызванные равномерным снятием нагрузки на участке выработки размером (10×2×0.3 км), моделирующей Бачатский карьер, составляют величины не более двух процентов от литостатического напряжения. Подобный результат совпадает с численными расчетами ряда авторов [Reshetnyak et al., 2012; Lovchikov, Savchenko, 2016] и, на первый взгляд, свидетельствует именно о незначительном влиянии выемки породы на напряженно-деформированное состояние массива горных пород на ве- 
роятной глубине расположения очагов сейсмических событий.

К вопросу о пороге значимости изменения поля квазистатических напряжений обращались многие авторы, чьи мнения зачастую оказывались противоположными. Так, авторы недавнего обзора [Foulger et al., 2018] на основании того, что «землетрясения происходят и без вмешательства человека», полагают, что инициирующим потенциалом обладает сколь угодно малое изменение поля напряжений. В работе [Keranen et al., 2014] отмечается, что антропогенные изменения напряжения, вызвавшие землетрясения, составляют доли МПа, а в работах [Klose, 2007, 2012] и вовсе приводится значение в несколько кПа. С другой стороны, в [Quinn et al., 2008; Lovchikov, 2016; и дp.] отмечается, что такие величины неприемлемо малы.

Несложно, однако, убедиться, что такие изменения параметров поля напряжений могут оказаться решающими. Одним из немногих достаточно надежных источников сведений об инициировании динамических подвижек являются последовательности афтершоков. Считается, что одной из вероятных причин афтершоков является изменение в результате подвижки в очаге соотношения между нормальными и касательными напряжениями на плоскости некоторых разломов, расположенных в окрестности основного разрыва [Das, Scholz, 1981; King et al., 1994; и $\partial p$.]. В зависимости от геометрии очага основного землетрясения, расположения и ориентации относительно него соседних разломов, изменение поля напряжений в результате подвижки либо «подталкивает» соседние разломы несколько ближе к порогу разрушения, либо, наоборот, делает их стабильнее. Этот эффект часто описывают при помощи оценки вариации функции Кулона на ориентированной определенным образом площадке:

$$
\sigma_{c}=\tau-\mu\left(\sigma_{n}-p\right)
$$

где $\sigma_{n}$ и $\tau$ - нормальное и касательное к плоскости разлома напряжения, $p$ - поровое давление и $\mu$ коэффициент трения.

На стадии подготовки динамического срыва $\sigma_{c}<0$. В случае увеличения касательного напряжения $\tau$ или снижения эффективного нормального напряжения $\left(\sigma_{n}-p\right)$ разлом приближается к критическому состоянию $\sigma_{c}=0$. Подчеркнем, что даже не зная абсолютных величин напряжений, можно вычислить изменение функции Кулона, используя инкрементальное уравнение:

$$
\Delta \sigma_{c}=\Delta \tau-\mu\left(\Delta \sigma_{n}-\Delta p\right),
$$

из которого можно понять, был ли разлом подведен ближе к критическому состоянию (положи- тельное приращение $\Delta \sigma_{c}>0$ ), или, наоборот, отодвинут в более стабильное состояние $\left(\Delta \sigma_{c}<0\right)$. Для этих расчетов не требуется сведений о НДС в регионе и не рассматриваются поля напряжений от других источников.

«Кулоновская теория инициирования» получила широкое распространение, явившись одним из популярных объяснений того, что афтершоки землетрясения проявляются не только в пределах разломной зоны, но также и в соседних областях [Das, Scholz, 1981]. Сопоставление результатов расчетов изменений статического поля напряжений с распространенностью афтершоков показывает, что изменение напряжений $\Delta \sigma_{c}$ порядка 0.1-0.3 МПа часто оказывается достаточным для инициирования сейсмичности, в то время как снижение на ту же величину сдерживает еe [King et al., 1994; $и$ дp.]. Такие малые величины, являясь незначительной частью общего сброса напряжений при землетрясении, указывают на то, что квазистатические изменения напряжений не являются причиной землетрясения, а только приближают или удаляют момент события. Отметим, что такая картина наблюдается не всегда. Так, только $60 \%$ афтершоков землетрясения $M_{w}=6.7$ Northridge 1994 г. находились в области увеличения кулоновского напряжения [Hardebeck et al., 1998], а в работе [Felzer, Brodsky, 2003] не выявлено никакой значительной связи между областями с пониженным уровнем сейсмичности и их расположением относительно разлома землетрясения Landers.

Для того чтобы корректно выбрать ориентацию разлома, обратимся к результатам рассмотрения сведений о геолого-тектоническом строении участка. Судя по приведенным выше данным, при проведении расчетов в качестве сейсмического источника Бачатского события 18.06.2013 г. следует рассматривать подвижку в юго-западном направлении по одному из разломов с углом падения $\sim 10^{\circ}$ на глубине 4-6 км, т.е. вдоль длинной оси Бачатского карьера.

Величины вариации функции Кулона на плоскости разлома с углом падения $10^{\circ}$ приведены на рис. 7. Показан результат расчета вдоль центральной оси плоскости разлома $(\mathrm{y}=0)$. Видно, что на глубине предполагаемого расположения гипоцентра землетрясения величина приращения кулоновского напряжения является положительной, т.е. подводящей разлом ближе к критическому состоянию. Изменение кулоновского напряжения при этом составляет для разных расчетных случаев величину около 1 МПа.

Крайне важно, что такое изменение кулоновского напряжения происходит на протяженном участке разломной плоскости, сопоставимом по размерам с длиной карьера, что заметно превышает зону нуклеации землетрясения $\mathrm{M} \leq 6$. 


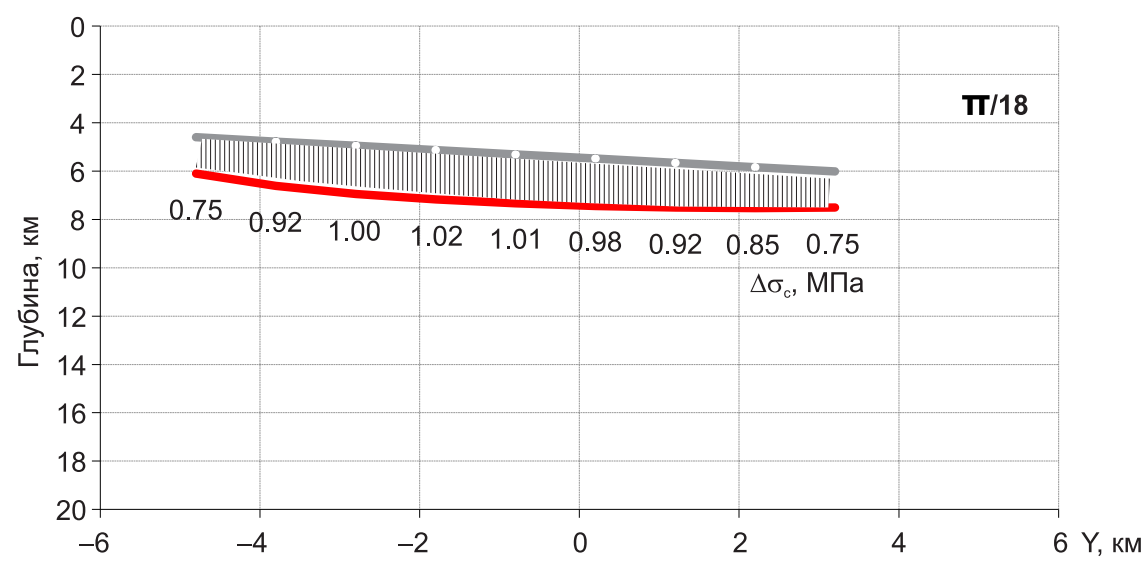

Рис. 7. Результаты расчета приращения кулоновского напряжения на плоскости разлома с углом падения $10^{\circ}$. Серая линия - положение плоскости разлома. Вариация функции Кулона показана в виде заштрихованной области и цифрами.

Fig. 7. Estimated increment of the Coulomb stress on the fault plane with a dip angle of $10^{\circ}$. Gray line - fault plane. Shaded area and numbers - variations in the Coulomb function.

Поскольку изменение кулоновских напряжений само по себе не в состоянии объяснить такие эффекты, как регулярно наблюдаемые задержки по времени между инициирующим и инициируемым событием, изменение скорости сейсмичности со временем, миграции эпицентров афтершоков к периферии и т.д., в статическую модель интегрируют более сложные закономерности трения, зависящего от скорости и перемещения, например «Rate\&State» модель [Dieterich, 1979]. Понятно, что может наблюдаться существенное отличие в реакции разлома на «мгновенное» изменение поля напряжений в результате динамической подвижки при землетрясении и на постепенное изменение кулоновских напряжений в результате многолетних работ по выемке и перемещению породы.

Для того чтобы проверить влияние фактора времени в рамках упомянутой модели «Rate\&State», были проведены численные расчеты процесса возникновения динамической неустойчивости в классической постановке слайдер-модели - жесткого блока, скользящего по шероховатой поверхности под действием силы, создаваемой пружиной жесткостью К при медленном движении ее свободного конца со скоростью $\dot{u}_{0}$.

При численном моделировании для описания фрикционного взаимодействия блока и подложки был использован закон «R\&S» в виде зависимости коэффициента трения $\mu$ от мгновенной скорости скольжения $V$ и от переменной состояния $\theta$ :

$$
\mu=\mu_{0}-a \ln \left(\frac{V_{0}}{V}+1\right)+b \ln \left(\frac{V_{0} \theta}{D_{c}}+1\right)
$$

где $\mu_{0}$ - константа, соответствующая стабильному скольжению, $V$ - текущая скорость смещения, $\theta-$ переменная состояния, $a, b, D_{c}, V_{0}$ - эмпирические константы. Величина $\theta$ изменяется со временем и перемещением по определенному закону (эволюционное уравнение) в процессе перехода контакта к новому стабильному состоянию. Наиболее известным является закон Дитриха [Dieterich, 1979]:

$$
\frac{d \theta}{d t}=1-\frac{V_{0} \theta}{D_{c}} .
$$

Уравнение, описывающее движение подвижного блока модели, имеет вид:

$$
m \ddot{\mathrm{x}}=K\left(u_{s} t-x\right)-S \cdot \tau_{s},
$$

где $m$ - масса, $S$ - площадь блока, $K$ - жесткость пружины, $u_{\mathrm{s}}$ - скорость протяжки пружины, $F_{S}=S \cdot \tau-$ сила сопротивления сдвигу, задаваемая в соответствии с уравнением (10).

Для численного решения дифференциального уравнения (12) совместно с уравнениями (10) и (11) использовался метод Рунге-Кутта 4-го порядка аппроксимации.

Константы, используемые в расчете, имели следующие значения: $\mu_{0}=0.4, a=0.0002, b=0.0082$, $D c=0.001 \mathrm{м}, \underline{V_{0}}=10^{-4} \mathrm{м} / \mathrm{c}, F_{\mathrm{n}}=2.5 \times 10^{6} \mathrm{H}, m=2.5 \times 10^{6}$ кг, $K=200 \mathrm{\kappa H} /$ м, скорость протяжки $V \mathrm{~s}=0.0003$ м/с.

На рис. 8, a, показана зависимость напряжения на контакте и скорости смещения блока от времени в опорном варианте расчета.

Параметры динамического срыва в опорном варианте сравнивались с характеристиками срыва при изменении величины нормального напряжения на контакте $\sigma_{n}$ на $1 \%$. При этом снижение величины нормального давления происходило либо мгновенно, либо в течение некоторого интервала 

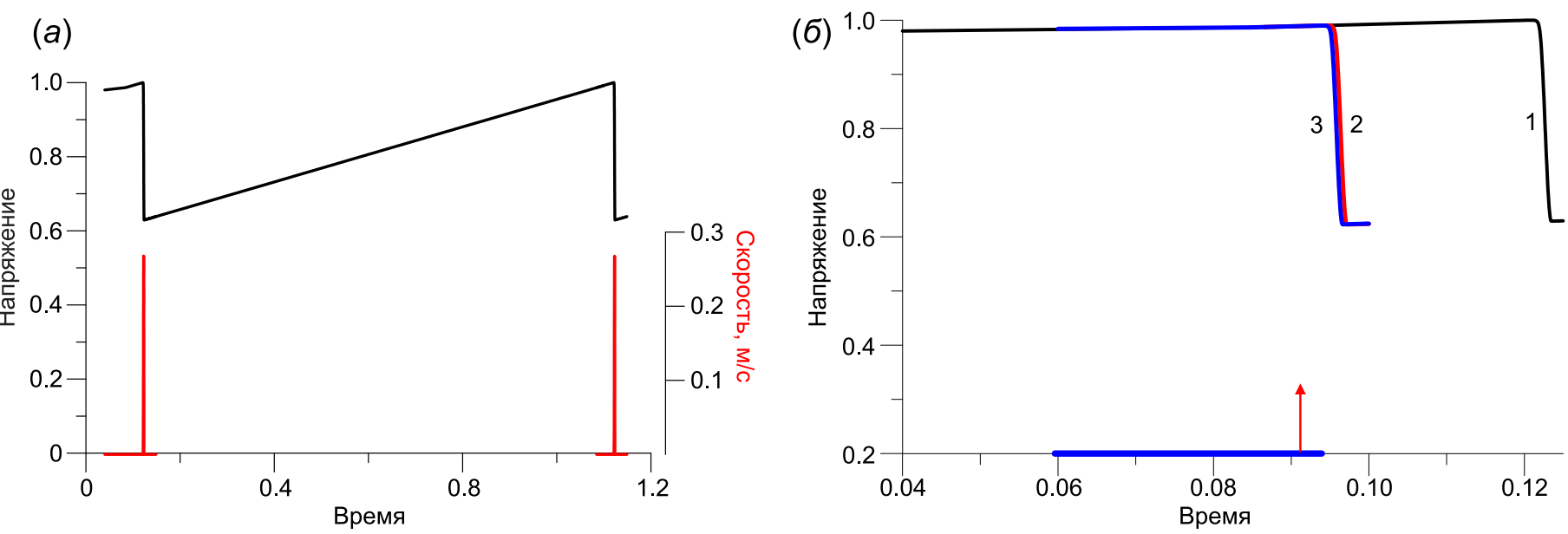

Рис. 8. Зависимость напряжения на контакте от времени: $a$ - равномерное нагружение при $\sigma_{n}=c o n s t ; \sigma$ - разные варианты нагружения: $1-\sigma_{n}=$ const; 2 - «мгновенное» снижение величины $\sigma_{n}$ на $1 \%$ в момент, показанный стрелкой; 3 - линейное снижение величины $\sigma_{n}$ на 1 \% в течение времени, показанного на оси абсцисс жирным отрезком. Время нормировано на рекуррентное время между срывами, а напряжение - на величину фрикционной прочности.

Fig. 8. Stress at the contact versus time: $a$ - uniform loading at $\sigma_{n}=$ const; $\sigma$ - different loading options: $1-\sigma_{n}=$ const; 2 - 'instant' decrease of value $\sigma_{n}$ by $1 \%$ at the moment shown by the arrow; 3 - linear decrease of value $\sigma_{n}$ by $1 \%$ within the time period shown on the abscissa axis by a thick segment. Time is normalized to the recurrence time between rock failures. Stress is normalized to the frictional strength.

времени длительностью от 0.015 до 0.045TR, где TR - рекуррентное время между срывами. Пример сопоставления нескольких вариантов показан на рис. 8, б. Как показали результаты расчета, и время срыва, и величина сброшенного напряжения, и максимальная скорость смещения блока примерно одинаковы в случае динамического и медленного снижения нормальной нагрузки.

\section{5. ЗАКЛЮЧЕНИЕ}

Землетрясение 18.06.2013 г. в Кузбассе с M=6.1 сильнейшее в истории сейсмическое событие, произошедшее в непосредственной близости от горнодобывающего предприятия - Бачатского угольного разреза. Большой масштаб явления, очевидная приуроченность его очага к зоне ведения горных работ, изученность как региона, так и распределения во времени уровня техногенного воздействия делают его весьма заманчивым для исследования процесса инициирования сейсмических событий.

В качестве возможных причин инициирования Бачатского события мы рассмотрели общий уровень антропогенной нагрузки на регион, непосредственное воздействие сейсмических колебаний от массовых взрывов, а также извлечение и перемещение горных масс из карьера.

Сравнение данных об объеме добычи и расходе BВ в районе Кузбасса с периодичностью возникно- вения сильных (с магнитудой $\mathrm{Mb}>4$ ) землетрясений, а также вариации энергии, излученной сильными землетрясениями региона, с ростом суммарного расхода ВВ предприятиями Кузбасса не выявили значимой корреляции.

Оценки возможности прямого инициирования сейсмическими колебаниями от массовых короткозамедленных взрывов крупного землетрясения с гипоцентром, располагающимся на глубине в несколько километров, продемонстрировали, что такое развитие событий едва ли возможно.

Анализ геолого-тектонического строения района, в совокупности с данными о расположении афтершоков Бачатского события, позволяет заключить, что вероятным источником колебаний при основном толчке была динамическая подвижка по разлому с углом падения порядка $10^{\circ}$ на глубине 4-6 км и простиранием СЗ-ЮВ.

Выполненный в упругой постановке аналитический 3D расчет изменения поля напряжений в окрестности выемки с размерами $10 \times 2 \times 0.3$ км показал, что вариация функции Кулона на плоскости такого разлома положительна и составляет величину порядка 1 МПа. При этом изменения происходят на обширном участке разлома, существенно превышающем характерный размер зоны нуклеации землетрясения с $\mathrm{M=6}$, что является необходимым условием для возникновения динамической подвижки. Сопоставление результатов расчетов с данными наблюдений за расположением афтершоков при зем- 
летрясениях показало, что таких вариаций может оказаться достаточно для инициирования.

Используемая Кулоновская теория инициирования афтершоков разработана для «мгновенного» изменения поля напряжений в массиве в результате подвижки по разлому. Изменение НДС в результате горных работ происходит со значительно меньшей скоростью. Чтобы проверить влияние фактора времени, были проведены численные расчеты процесса возникновения динамической неустойчивости в рамках модели «Rate\&State». Peзультаты расчета показали, что и время срыва, и величина сброшенного напряжения, и максимальная скорость смещения по разлому примерно одинаковы в случае мгновенного и медленного изменения напряженного состояния.
Судя по полученным результатам, основным триггером Бачатского землетрясения, скорее всего, явились горные работы - выемка и перемещение горной породы приблизили момент землетрясения, подготовленного естественной эволюцией коры.

\section{6. БЛАГОДАРНОСТИ}

Работа выполнена при финансовой поддержке Российского научного фонда (проект № 16-1700095) (Г.Г. Кочарян и С.Б. Кишкина). Исследования проводились в рамках государственного задания по проектам № 0146-2019-0001, № 0146-2019-0006 (А.М. Будков и Г.Н. Иванченко).

\section{7. ЛИТЕРАTУРА / REFERENCES}

Adushkin V.V., 2016. Tectonic earthquakes of anthropogenic origin. Izvestiya, Physics of the Solid Earth 52 (2), 173-194. https://doi.org/10.1134/S1069351316020014.

Adushkin V.V., 2018. Technogenic tectonic seismicity in Kuzbass. Russian Geology and Geophysics 59 (5), 571-583. https://doi.org/10.1016/j.rgg.2018.04.010.

Ashurkov V.A., 2006. Kuznetsk earthquakes in the south of Kuzbass and their connection with the geological structure. Natural Resources of Gorny Altai / Geology, geophysics, hydrogeology, geoecology, mineral and water resources (5), 65-74 (in Russian) [Ашурков B.A. Кузнецкие землетрясения юга Кузбасса и их связь с геологическим строением // Природные ресурсы Горного Алтая / Геология, геофизика, гидрогеология, геоэкология, минеральные и водные ресурсы. 2006. № 5. С. 65-74].

Avdeyev A.P., Cherepovsky V.F., Sharov G.N., Yuzvitsky A.Z. (Eds.), 2003. Coal Base of Russia. Vol. II. Coal Basins and Deposits of Western Siberia (Kuznetsky, Gorlovsky, West Siberian Basins; Deposits of the Altai Region and the Republic of Altai). Geoinformtsentr, Moscow, 604 p. (in Russian) [Угольная база России. Том 2. Угольные бассейны и месторождения Западной Сибири (Кузнецкий, Горловский, Западно-Сибирский бассейны, месторождения Алтайского края и Республики Алтай) / Ред. А.П. Авдеев, В.Ф. Череповский, Г.Н. Шаров, А.З. Юзвицкий. М.: Геоинформцентр, 2003. 604 с.].

Batugin A.S., 2015. Tectonophysical conditions for the manifestation of technogenic earthquakes. In: Modern problems in mining and methods for modeling mining and geological conditions in the development of mineral deposits. Proceedings of All-Russian scientific and technical conference with international participation. Kuzbass TF University, Kemerovo, p. 36 (in Russian) [Батугин A.C. Тектонофизические условия проявления техногенных землетрясений // Современные проблемы в горном деле и методы моделирования горно-геологических условий при разработке месторождений полезных ископаемых: Всероссийская научно-техническая конференция с международным участием. Кемерово: Кузбасский государственный технический университет, 2015. С. 36].

Bobryakov A.P., Kosykh V.P., Revuzhenko A.F., 2015. Trigger initiation of elastic energy relaxation in high-stress geomedium. Journal of Mining Science 51 (1), 10-16. https://doi.org/10.1134/S1062739115010020.

Das S., Scholz C.H., 1981. Off-fault aftershock clusters caused by shear stress increase? Bulletin of the Seismological Society of America 71 (5), 1669-1675.

Dieterich J.H., 1979. Modeling of rock friction: 1. Experimental results and constitutive equations. Journal of Geophysical Research: Solid Earth 84 (B5), 2161-2168. https://doi.org/10.1029/JB084iB05p02161.

Ellsworth W.L., Beroza G.C., 1995. Seismic evidence for an earthquake nucleation phase. Science 268 (5212), $851-855$. https://doi.org/10.1126/science.268.5212.851.

Emanov A.F., Emanov A.A., Fateev A.V., Leskova E.V., 2017. The technogenic Bachat earthquake of June 18, 2013 $(M L=6.1)$ in the Kuznetsk Basin - the world's strongest in the extraction of solid minerals. Seismic Instruments 53 (4), 333-355. https://doi.org/10.3103/S0747923917040041.

Emanov A.F., Emanov A.A., Fateev A.V., Leskova E.V., Shevkunova E.V., Podkorytova V.G., 2014. Mining-induced seismicity at open pit mines in Kuzbass (Bachatsky earthquake on June 18, 2013). Journal of Mining Science 50 (2), 224-228. https://doi.org/10.1134/S1062739114020033.

Felzer K.R., Brodsky E.E., 2004. The absence of stress shadows. Seismological Research Letters 75 (2), 285. https:// doi.org/10.1785/gssrl.75.2.219. 
Florin V.A., 1959. Fundamentals of Soil Mechanics. Vol. 1. Stroiizdat, Leningrad, 356 p. (in Russian) [Флорин В.А. Основы механики грунтов. Л.: Стройиздат, 1959. Т. 1. 356 с.].

Foulger G.R., Wilson M.P., Gluyas J.G., Julian B.R., Davies R.J., 2018. Global review of human-induced earthquakes. EarthScience Reviews 178, 438-514. https://doi.org/10.1016/j.earscirev.2017.07.008.

Goncharov A.I., Kulikov V.I., Martinson N.M., 2002. On the seismic effect of mass explosions in the open-pit mines of the КMA. Mine Analytical Bulletin (1), 162-164 (in Russian) [Гончаров А.И., Куликов В.И., Мартинсон Н.М. О сейсмическом действии массовых взрывов на карьерах КМА // Горный информационно-аналитический бюллетень. 2002. № 1. С. 162-164].

Goncharov A.I., Kulikov V.I., Mineev V.I., Sedochenko V.V., 2006. Seismic effect of mass explosions in underground and open works. In: Dynamic processes in interacting geospheres. GEOS, Moscow, p. 22-33 (in Russian) [Гончаров А.И., Куликов В.И., Минеев В.И., Седоченко В.В. Сейсмическое действие массовых взрывов на открытых и подземных работах // Динамические процессы во взаимодействующих геосферах. М.: ГЕОС, 2006. С. 22-33].

Hardebeck J.L., Nazareth J.J., Hauksson E., 1998. The static stress change triggering model: Constraints from two southern California aftershock sequences. Journal of Geophysical Research: Solid Earth 103 (B10), 24427-24437. https://doi.org/10.1029/98JB00573.

Heesakkers V., Murphy S., Lockner D.A., Reches Z., 2011. Earthquake rupture at focal depth, Part II: Mechanics of the 2004 M2.2 earthquake along the pretorius fault, TauTona Mine, South Africa. Pure and Applied Geophysics 168 (12), 2427-2449. https://doi.org/10.1007/s00024-011-0355-6.

Ide S., Takeo M., 1997. Determination of constitutive relations of fault slip based on seismic wave analysis. Journal of Geophysical Research: Solid Earth 102 (B12), 27379-27391. https://doi.org/10.1029/97JB02675.

Keranen K.M., Weingarten M., Abers G.A., Bekins B.A., Ge S., 2014. Sharp increase in central Oklahoma seismicity since 2008 induced by massive wastewater injection. Science 345 (6195), 448-451. https://doi.org/10.1126/science. 1255802.

King G.C., Stein R.S., Lin J., 1994. Static stress changes and the triggering of earthquakes. Bulletin of the Seismological Society of America 84 (3), 935-953.

Kishkina S.B., 2004. Parameters of seismic effect of mass short-delayed explosions. NNC RK Bulletin (2), 171-178.

Klose C.D., 2007. Geomechanical modeling of the nucleation process of Australia's 1989 M5.6 Newcastle earthquake. Earth and Planetary Science Letters 256 (3-4), 547-553. https://doi.org/10.1016/j.epsl.2007.02.009.

Klose C.D., 2012. Evidence for anthropogenic surface loading as trigger mechanism of the 2008 Wenchuan earthquake. Environmental Earth Sciences 66 (5), 1439-1447. https://doi.org/10.1007/s12665-011-1355-7.

Kocharyan G.G., 2012. Triggering of natural disasters and technogeneous emergeneous emergencies by low amplitude seismic waves. Geoekologiya (Geoecology) (6), 483-496 (in Russian) [Кочарян Г.Г. Инициирование природных катастроф и техногенных аварий сейсмическими колебаниями малой амплитуды // Геоэкология. 2012. № 6. С. 483-496].

Kocharyan G.G., 2014. Scale effect in seismotectonics. Geodynamics \& Tectonophysics 5 (2), 353-385 (in Russian) [Кочарян Г.Г. Масштабный эффект в сейсмотектонике // Геодинамика и тектонофизика. 2014. Т. 5. № 2. C. 353-385]. https://doi.org/10.5800/GT-2014-5-2-0133.

Kocharyan G.G., 2016. Geomechanics of Faults. GEOS, Moscow, 424 p. (in Russian) [Кочарян Г.Г. Геомеханика разломов. М.: ГЕОС, 2016. 424 с.].

Kocharyan G.G., Kostyuchenko V.N., Pavlov D.V., 2004. Crustal deformation induced by weak disturbances. Fizicheskaya Mezomekhanika (Physical Mesomechanics) 7 (1), 5-22 (in Russian) [Кочарян Г.Г., Костюченко В.Н., Павлов Д.В. Инициирование деформационных процессов в земной коре слабыми возмущениями // Физическая мезомеханика. 2004. Т. 7. № 1. С. 5-22].

Kocharyan G.G., Ostapchuk A.A., Pavlov D.V., 2013. Deformation mode of fault zones and the initiating potential of seismic vibrations. In: V.V. Adushkin, G.G. Kocharyan (Eds.), Trigger effects in geosystems. Materials of the second AllRussian seminar-meeting. GEOS, Moscow, p. 34-45 (in Russian) [Кочарян Г.Г., Остапчук А.А., Павлов Д.В. Режим деформирования разломных зон и инициирующий потенциал сейсмических колебаний // Триггерные эффекты в геосистемах / Ред. В.В. Адушкин, Г.Г. Кочарян. М.: ГЕОС, 2013. С. 34-45].

Korotkin V.G., 1938. Volumetric problem for elastic-isotropic half-space. In: Gidroenergoproekt collection of papers. Issue 4. State Joint Scientific and Technical Publishing House, Leningrad-Moscow, p. 52-85 (in Russian) [Короткин В.Г. Объемная задача теории упруго-изотропного полупространства // Сборник Гидропроекта. № 4. Л.-М.: ГОНТИ, 1938. С. 52-85].

Kremenetskaya E.O., Trjapitsin V.M., 1995. Induced seismicity in the Khibiny Massif (Kola Peninsula). Pure and Applied Geophysics 145 (1), 29-37. https://doi.org/10.1007/BF00879481.

Kudinov E.V., 2007. Geology-tectonic constructions verhnebalahonskaya series and gas content coals ProkopievskKiselevsk segment of Prisalairskaya zone of the Kuzbass. Tomsk State University Journal 301, 196-200 (in Russian) [Кудинов E.В. Геолого-тектоническое строение и газоносность угленосных отложений верхнебалахонской подсерии Прокопьевско-Киселевского сегмента Присалаирской зоны Кузбасса // Вестник Томского государственного университета. 2007. № 301. С. 196-200]. 
Lavrenov P.F., Snezhko B.A., Shchigrev A.F. et al., 2018. The State Geological Map of the Russian Federation. Scale 1:200000. Second edition. Kuzbass series. Sheet N-45-XV (Leninsk Kuznetsky). Explanatory note. Moscow branch of the VSEGEI, Moscow, 115 p. (in Russian) [Лавренов П.Ф., Снежко Б.А., Щигрев А.Ф. и др. Государственная геологическая карта Российской Федерации. Масштаб 1:200000. Издание второе. Серия Кузбасская. Лист N-45-XV (Ленинск-Кузнецкий). Объяснительная записка. М.: Московский филиал ВСЕГЕИ, 2018. 115с.].

Lovchikov A.V., 2013. Review of the strongest rockbursts and mining-induced earthquakes in Russia. Journal of Mining Science 49 (4), 572-575. https://doi.org/10.1134/S1062739149040072.

Lovchikov A.V., 2016. Some patterns of mountain-tectonic impacts manifestation and man-made earthquakes in Russian mines. In: Forecasting and prevention of tectonic rock impacts and earthquakes: measurement of deformations, residual and operating stresses in rocks. Kyrgyz Academy of Sciences, Bishkek, p. 39-49 (in Russian) [Ловчиков А.B. Некоторые закономерности проявления горно-тектонических ударов и техногенных землетрясений на рудниках России // Прогноз и предупреждение тектонических горных ударов и землетрясений: измерение деформаций, остаточных и действующих напряжений в горных породах. Бишкек: НАН КР, 2016. С. 39-49].

Lovchikov A.V., Savchenko S.N., 2016. On the technogenic nature of the Bachatsky earthquake 06.18.2013. In: Tectonophysics and topical issues of Earth sciences. Proceedings of the Fourth Tectonophysical conference. Institute of Physics of the Earth of RAS, Moscow, p. 478-480.

Love A.E.H., 1927. A Treatise on the Mathematical Theory of Elasticity. Fourth edition. Cambridge University Press, Cambridge, 643 р. [Русский перевод: Ляв А. Математическая теория упругости (перевод с 4-го английского издания). М.-Л.: ОНТИ НКТП СССР, 1935. 674 с.].

Melnikov N.N. (Ed.), 2002. Seismicity During Mining. Publishing House of the KSC RAS, Apatity, 318 p. (in Russian) [Сейсмичность при горных работах / Ред. Н.Н. Мельников. Апатиты: Изд-во Кольского научного центра PAH, 2002. 318 c.].

Mukhamediev Sh.A., 2016. On discrete structure of geologic medium and continual approach to modeling its movements. Geodynamics \& Tectonophysics 7 (3), 347-381 (in Russian) [Мухамедиев Ш.А. О дискретном строении геосреды и континуальном подходе к моделированию ее движения // Геодинамика и тектонофизика. 2016. Т. 7. № 3. С. 347-381]. https://doi.org/10.5800/GT-2016-7-3-0213.

Novikov I.S., Cherkas O.V., Mamedov G.M., Simonov Y.G., Simonova T.Y., Nastavko V.G., 2013. Activity stages and tectonic division in the Kuznetsk Basin, Southern Siberia. Russian Geology and Geophysics 54 (3), 324-334. https://doi.org/ 10.1016/j.rgg.2013.02.007.

Ovsyuchenko A.N., Rogozhin E.A., Novikov S.S., Marakhanov A.V., Larkov A.S., 2011. Paleogeological and tectonic studies to clarify the natural and man-made hazard of the south of Kuzbass. Natural and Man-Made Risks. Building Safety (1), 65-74 (in Russian) [Овсюченко А.Н., Рогожин Е.А., Новиков С.С., Мараханов А.В., Ларько А.С. Палеогеологические и тектонические исследования по уточнению природно-техногенной опасности юга Кузбасса // Природные и техногенные риски. Безопасность сооружений. 2011. № 1. С. 65-74].

Papageorgiou A.S., Aki K., 1983. A specific barrier model for the quantitative description of inhomogeneous faulting and the prediction of strong ground motion. Part II. Applications of the model. Bulletin of the Seismological Society of America 73 (4), 953-978.

Quinn C.D., Glen R.A., Diessel C.F.K., 2008. Discussion of "Geomechanical modeling of the nucleation process of Australia's 1989 M5.6 Newcastle earthquake" by C.D. Klose [Earth Planet. Sci. Lett. 256 (2007) 547-553]. Earth and Planetary Science Letters 269 (1-2), 296-302. https://doi.org/10.1016/j.epsl.2007.11.067.

Reshetnyak S.P., Fedotova Yu.V., Savchenko S.N., 2012. Deep open pit walls design using rock mass stress-strained state Journal of Mining Institute 197, 169-173 (in Russian) [Решетняк С.П., Федотова Ю.В., Савченко С.Н. Особенности проектирования формы глубоких карьеров с учетом напряженно-деформированного состояния вмещающего массива горных пород // Записки Горного института. 2012. T. 197. С. 169-173].

Rymer M.J., Boatwright J., Seekins L.C., Yule J.D., Liu J., 2002. Triggered surface slips in the Salton Trough associated with the 1999 Hector Mine, California, earthquake. Bulletin of the Seismological Society of America 92 (4), 1300-1317. https://doi.org/10.1785/0120000935.

Scholz C.H., 1998. Earthquakes and friction laws. Nature 391 (6662), 37-42. https://doi.org/10.1038/34097.

Sharov G.N., Chernykh A.E., 2006. Peculiarities of the Kuznykaya Depression deep structure due to oil and gas and ore bearing. In: M.I. Kuzmin (Ed.), Actual problems of ore formation and metallogeny. Geo, Novosibirsk, p. 243-245 (in Russian) [Шаров Г.Н., Черных А.Е. Особенности глубинного строения Кузнецкой впадины в связи с нефтегазо- и рудоносностью // Актуальные проблемы рудообразования и металлогении / Ред. М.И. Кузьмин. Новосибирск: Гео, 2006. С. 243-245].

Shemyakin E.I., Kurlenya M.V., Kulakov G.I., 1986. Classification of rock bursts. Journal of Mining Science 22 (5), 329-336. https://doi.org/10.1007/BF02504138.

State Geological Map, 2007. Scale 1:1000000 (third generation). Sheet N-45, Novokuznetsk. VSEGEI, Saint Petersburg (in Russian) [Государственная геологическая карта. Масштаб 1:1000000 (третье поколение). Лист N-45, Новокузнецк. СПб.: ВСЕГЕИ, 2007].

Sysoev E.S., Strelyaev V.I., 2007. Analysis of the geodynamic evolution of the coal-bearing geological structures of the Prisalair zone of Kuzbass. In: Problems and prospects for the development of the mineral resource base of the 
enterprises of the fuel and energy complex of Siberia. Proceedings of the interregional scientific-practical conference. Tomsk State University, Tomsk, p. 297-304 (in Russian] [Сысоев Е.С., Стреляев В.И. Анализ геодинамической эволюции углевмещающих геологических структур Присалаирской зоны Кузбасса // Проблемы и перспективы развития минерально-сырьевой базы и предприятий ТЭК Сибири: Материалы межрегиональной научно-практической конференции. Томск: ТГУ, 2007. С. 297-304].

Wells D.L., Coppersmith K.J., 1994. New empirical relationships among magnitude, rupture length, rupture width, rupture area, and surface displacement. Bulletin of the Seismological Society of America 84 (4), 974-1002.

Yakovlev D.V., Lazarevich T.I., Tsirel' S.V., 2013. Natural and induced seismic activity in Kuzbass. Journal of Mining Science 49 (6), 862-872. https://doi.org/10.1134/S1062739149060038.

\section{Геворг Грантович Кочарян}

докт. физ.-мат. наук, зав. лабораторией,

заместитель директора

Институт динамики геосфер РАН

119334, Москва, Ленинский проспект, 38, корп. 1, Россия

$\triangle$ e-mail: gevorgkidg@mail.ru

(iD) https://orcid.org/0000-0002-8343-5127

\section{Александр Михайлович Будков}

докт. техн. наук

Институт динамики геосфер РАН

119334, Москва, Ленинский проспект, 38, корп. 1, Россия

D https://orcid.org/0000-0002-3126-002X

\section{Светлана Борисовна Кишкина}

канд. физ.-мат. наук

Институт динамики геосфер РАН

119334, Москва, Ленинский проспект, 38, корп. 1, Россия

e-mail: SvetlanK@gmail.com

(iD) https://orcid.org/0000-0003-4714-9761

Галина Николаевна Иванченко

канд. физ.-мат. наук

Институт динамики геосфер РАН

119334, Москва, Ленинский проспект, 38, корп. 1, Россия

e-mail: ivanchenko@idg.chph.ras.ru

(iD) https://orcid.org/0000-0003-4967-6418

\section{Gevorg G. Kocharyan}

Doctor of Physics and Mathematics, Head of Laboratory, Deputy Director

Institute of Geosphere Dynamics of RAS

38 Leninsky prospect, Building 1, Moscow 119334, Russia

\section{Aleksander M. Budkov}

Doctor of Technical Sciences

Institute of Geosphere Dynamics of RAS

38 Leninsky prospect, Building 1, Moscow 119334, Russia

\section{Svetlana B. Kishkina}

Candidate of Physics and Mathematics

Institute of Geosphere Dynamics of RAS

38 Leninsky prospect, Building 1, Moscow 119334, Russia

\section{Galina N. Ivanchenko}

Candidate of Physics and Mathematics

Institute of Geosphere Dynamics of RAS

38 Leninsky prospect, Building 1, Moscow 119334, Russia 